UDK: 004.42:004.738.12

DOI: $\underline{\text { https://doi.org/10.24867/16BE24Jeftic }}$

\title{
UPOTREBA DINAMIČKOG DNS-A ZA LAK PRISTUP KUĆNOJ MREŽI SA BILO KOG UDALJENOG MESTA
}

\section{EASILY ACCESS HOME NETWORK FROM ANYWHERE WITH DYNAMIC DNS}

\author{
Vanja Jeftić, Fakultet tehničkih nauka, Novi Sad
}

\section{Oblast - PRIMENJENE RAČUNARSKE NAUKE}

Kratak sadržaj - U ovom radu opisana je konfiguracija $i$ upotreba dinamičkog DNS-a za lak pristup kućnoj mreži sa bilo kog udaljenog mesta. Govoriće se o DNS-u, o njegovim bitnim elementima, dinamičkom DNS-u $i$ o konfiguraciji istog. Dat je $i$ primer kreiranja testnog servera i podešavanja DDNS-a u okviru tog servera.

Ključne reči: $D N S, I P, D D N S$

\begin{abstract}
This paper describes the configuration and use of dynamic DNS for easy access to the home network from any remote location. There will be talk about DNS, its essential elements, dynamic DNS, and its configuration. An example of creating a test server and setting up DDNS within that server is also given.
\end{abstract}

Keywords: $D N S, I P, D D N S$

\section{UVOD}

Veliki broj korisnika ima sadržaje u okviru svoje kućne mreže, kojima bi voleo da pristupi sa nekog udaljenog mesta. Rešenje za pomenuti problem nudi dinamički DNS. Za objašnjenje rešenja ovog problema potrebno je prvo razumeti kako funkcioniše DNS (eng. Domain Name System).

Internet predstavlja ogromnu mrežu uređaja, svaki od tih uređaja ima svoju oznaku, kako bi drugi uređaji mogli da ga identifikuju. Ta oznaka se zove IP adresa. O IP adresi će se detaljnije govoriti dalje u radu, za sada je dovoljno razumevanje da IP adresa predstavlja niz grupisanih brojeva, razdvojenih tačkom, dužine 32 bita (primer 192.168.1.1). Teško je zamisliti situaciju u kojoj bi svaki korisnik koji bi želeo da ostvari komunikaciju sa drugim uređajem ili situaciju kada bi želeo da poseti neki sajt, morao da pamti IP adresu tog uređaja ili IP adresu web sajta.

Korisnik $\mathrm{u}$ internet pretraživač unosi ime poput „example.com“ i dobija rezultat koji odgovara tom imenu. To ime se zove domensko ime (eng. Domain name). Veza između pomenutih IP adresa i domenskog imena je DNS. DNS možemo zamisliti kao veliki telefonski imenik, u kome se nalaze pomenute IP adrese i njima odgovarajuća domenska imena. O ostalim pojmovima DNS-a će se detaljnije govoriti u okviru druge oblasti. Treća oblast je posvećena dinamičkom DNS-u ili skraćeno DDNS-u.

\section{NAPOMENA:}

Ovaj rad proistekao je iz master rada čiji mentor je bio Docent Željko Vuković.
Kratko objašnjenje pojma bi bilo, da je to usluga koja omogućava korisniku da pristupi svom kućnom računaru sa bilo kog mesta u svetu. U okviru treće oblasti se može naći i primer direktne primene konfiguracije DDNS-a na testnom serveru.

\section{DNS - (DOMAIN NAME SYSTEM)}

\subsection{Uopšteno o DNS-u}

Gotovo svi korisnici koji koriste internet, koriste i DNS servis, a da toga nisu ni svesni. DNS je jedan od osnovnih servisa na internetu i predstavlja hijerarhijski uređen sistem, u kome se nalaze razne informacije, ali u najvećoj meri su zastupljeni podaci o IP adresama i domenskim imenima, kao i slovnim nazivima računara (eng. Hostname). Hostname predstavlja jedinstveno ime unutar neke mreže, koje koriste razni protokoli za elektronsku identifikaciju nekog računara. Klijentima DNS informacije pružaju DNS serveri, upotrebom DNS protokola za komunikaciju sa klijentima. Svrha i razlog kreiranja DNS-a je da se pojednostavi komunikacija između više računara i komunikacija između korisnika i računara odnosno interneta, jer više nije potrebno pamtiti nizove brojeva koji se nazivaju IP adrese, nego je dovoljno zapamtiti slovne nazive koji odgovaraju tim IP adresama.

\subsection{IP adrese}

Internet protokol ili skraćeno IP, je protokol koji sadrži podatke o adresiranju, čime se postiže da svaki mrežni uređaj koji je povezan na internet ima jedinstvenu adresu $i$ može se lako identifikovati u celoj internet mreži, a takođe sadrži i kontrolne informacije koje omogućuju paketima da budu prosleđeni na osnovu poznatih IP adresa. Postoje dve verzije internet protokola koje su u upotrebi, verzija 4 (IPv4) i verzija 6 (Ipv6). Tokom dalje obrade teme, govoriće se o verziji 4 , jer je ona i dalje više rasprostanjena [1].

IP adresa se sastoji iz dva dela, prvi deo predstavlja adresu IP mreže, koja je ista za sve računare na jednoj IP mreži i deo koji predstavlja adresu računara koji je jedinstven za svaki računar na toj istoj IP mreži. Prvi deo adrese služi za identifikovanje mreže, a drugi deo za identifikovanje računara koji je povezan na računarsku mrežu. IP adrese mogu biti javne i privatne. Javne se mogu koristiti na internetu za razliku od privatnih koje su namenjene mrežama i nisu direktno povezane na internet, stoga se ne mogu koristiti na internetu. 


\subsection{Domensko ime}

Domensko ime je simboličko ime računara, koje ga jedinstveno identifikuje na internetu. DNS preslikava domensko ime u jednu ili više IP adresa i obrnuto. Dat je primer kako izgleda FQDN (енг. Fully Qualified Domain Name), koji predstavlja više labela - niz alfanumeričkih znakova sa maksimalno 63 znaka unutak svake labele, koje zajedno formiraju domesko ime.

FQDN: $\quad$ www.ftn.uns.ac.rs.

лабеле: $\quad$ www, ftn, uns, ac, rs

име рачунара: www

доменско име: ftn.uns

top-level домен: ac.rs

\subsection{Domen}

Domenska imena su uglavnom grupisana. Kriterijum grupisanja zavisi od labele kojom se ta domenska imena završavaju. Takve završne labele se nazivaju TLD (eng. Top-Level Domain) imena i postove dva tipa. Prvi tip su geografski bazirani domeni ili takozvani ccTLD (eng. Country code TLD). Drugi tip su generički domeni ili gTLD (eng. Generic TLD) domeni koji se uglavnom sastoje od tri ili više znakova. U jednom domenskom prostoru na mogu da postoje dve iste labele. Primer TLDa:

gTLD: .com, .net, .org, .biz, .info, .museum, .travel, .xxx ccTLD: .hr, .us, .eu, .fr, .es, .de, .it, .jp, ...

\subsection{Registar imena domena - domenski registri}

Domenski registri su baze podataka koje sadrže podatke o domenima i njima odgovarajućim IP adresama. Svaki TLD-Top-Level Domen ima svoj domenski registar.

\subsection{DNS rezolucija}

Rezolucija predstavlja proces primanja zahteva i obrade istog, te vraćanja odgovora na osnovu primljenog zahteva. Osnovna rezolucija je proces pretvaranja domenskog imena u IP adresu. Postoje dva osnovna tipa rezolucije, odnosno dva osnovna tipa prolaska kroz DNS hijerarhiju kako bi se otkrio tačan DNS zapis. Razlikuju se po tome ko obavlja većinski deo posla oko prikupljanja podataka i njihove obrade.

Iterativni tip rezolucije: situacija kada klijent šalje upite, a server odgovora sa jednim od dva moguća odgovora, ili odgovorom na zahtev ili imenom drugog DNS servera koji ima više podataka o traženom upitu.

Rekurzivni tip rezolucije: situacija kada klijent pošalje upit koji je rekurzivnog tipa, server preuzima posao pronalaženja informacija o traženom upitu. U ovom tipu, klijent šalje samo jedan zahtev i dobija ili tražene podatke ili poruku o grešci.

Rekurzivni tip pretraživanja je mnogo povoljniji za klijente od iterativnog, ali on može da optereti DNS servere u velikoj meri, stoga se takve forme upita dopuštaju samo računarima iz lokalne mreže.

\subsection{DNS keš}

Iterativni i rekurzivni prolazak kroz DNS stablo u cilju pretraživanja su bili veoma neefikasni [2], jer se za svaki upit moralo prolaziti kroz novo stablo. Sa ovakvim načinom rada, svaki upit bi predugo trajao. Rešenje za dati problem predstavlja DNS keš memorija. Način funkcionisanja se zasniva na činjenici da ako se nekom resursu nedavno pristupalo veće su šanse da će mu se ponovo pristupati. Stoga svi DNS serveri imaju internet keš memorije o nedavnim DNS upitima koji im omogućavaju da dobiju odgovor ili deo odgovora upravo iz te keš memorije. Time se smanjuje saobraćaj zahteva kao i vreme potrebno za pribavljanje nekog resursa.

\subsection{DNS obrnuta rezolucija}

Standardna rezolucija pretvara DNS imena u IP adrese. U standardnoj komunikaciji preko interneta, potrebno je obezbediti proces rezolucije u oba smera. Primer obrnute rezolucije bi bila provera da li određena adresa spada $u$ neki domen. Problem kod ove rezolucije je da se serveri razlikuju prvenstveno po labelama odnosno po domenima za koje su nadležni, a potrebno je vratiti IP adresu kao povratnu informaciju. Da bi se omogućio ovaj proces, formirana je dodatna hijerarhije u vidu INADDR.ARPA domena. Radi se o domenskom prostoru koji se sastoji od četiri nivoa poddomena, a svaki nivo odgovara jednom delu IP adrese. Obrnutom DNS rezolucijom, odnosno prolaskom kroz četiri nivoa poddomena, dolazi se do čvora za traženu IP adresu koji pokazuje na odgovarajuće domensko ime.

\subsection{DNS zona}

DNS zona može da sadrži zapise za jedan domen ili za više domena. Zapis je tekstualni fajl koji opisuje DNS zonu. DNS dozvoljava da DNS adresni prostor bude podeljen $u$ zone. Za svako domensko ime koje je uključeno u zonu, ta zona postaje autoritativni izvor za informacije koje se odnose na taj domen.

\subsection{Način rada DNS-a}

Kada korisnik unese određenu IP adresu $\mathrm{u}$ internet pretraživač, pretraživač u tom trenutku šalje zahtev putem interneta sa ciljem da dobije odgovor koji odgovara unetoj IP adresi. Taj zahtev dolazi do prve tačke obrade, koju obavlja DNS Resolver. On predstavlja posrednika između klijenta i DNS servera. DNS resolver zna u kom dalje smeru da uputi zahtev, odnosno na koji dalje DNS server da ga usmeri.

\section{DINAMIČKI DNS}

\subsection{Uvod}

Tema ovog rada je rešenje problema pristupa kućnom uređaju, računaru na primer, sa bilo koje udaljene lokacije. Da bi ovako nešto bilo moguće potrebno je da se korisnik opredeli za provajder koji omogućava uspostavljanje dinamičkog DNS-a, kao i da zna kako da konfiguriše svoj ruter.

DDNS (eng. Dynamic Domain Name System) je veoma sličan DNS-u, ali postoji razlika u tome što on pronalazi dinamičku IP adresu i upućuje na domen i obrnuto. Korisnici dobijaju IP adrese od njihovih internet provajdera $\mathrm{i}$ one se menjaju na određeni vremenski period. Da bi se rešio problem promenljive IP adrese, 
uvodi se DDNS, preko koga se dodeljuje stalno ime IP adresi korisnikove kućne mreže sa automatskim ažuriranjem kako se adresa menja tokom vremena. Kada je DDNS podešen, korisniku je omogućeno da pristupi kućnoj mreži jednostavnim unosom dodeljenog statičkog imena. Na Slika 1. je prikazano kako izgleda pristup kućnoj mreži sa bilo koje lokacije.

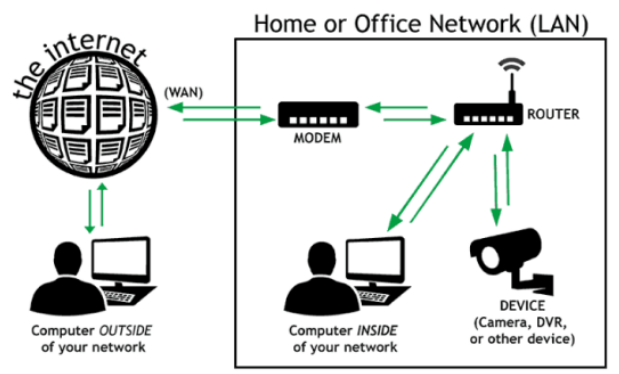

Slika 1. Pristup kućnoj mreži sa bilo koje lokacije [3]

\subsection{DNS Host}

Konfigurisanje DNS-a je jednostavno i besplatno za korisnike, i jednom kada se DNS podesi, nije potrebno održavanje tokom vremena. Da bi se konfigurisao DNS, potreban je DNS Host. Na tržištu postoji dosta dobrih provajdera koji nude besplatan DNS hosting, kao što su No-IP, Dynu Systems и Zonomi DNS.

\subsection{Ruter sa DDNS podrškom}

Veoma je bitno obezbediti ruter koji podržava DDNS usluge, kako bi nakon uključivanja podataka o DDNS provajderu, ruter mogao automatski da ažurira adresu. Dokle god je ruter uključen, DDNS adresa će uvek biti ažurirana. Ukoliko korisnikov ruter ne podržava DDNS usluge, biće potreban lokalni klijent za pokretanje na često korišćenom računaru negde u korisnikovoj kućnoj mreži. Ova aplikacija će proveriti korisnikovu IP adresu, a zatim će se obratiti DDNS provajderu radi ažuriranja korisnikovog DDNS zapisa.

\subsection{Konfigurisanje automatskog ažuriranja preko računara}

Ažuriranje zasnovano na ruteru je daleko moćnije od korišćenja programa za ažuriranje preko računara, ali ukoliko korisnik nema ruter koji je prilagođen aktivnostima DDNS-a, jedini način za automatizaciju procesa ažuriranja pruža progam za ažuriranje zasnovan na računaru.

\subsection{Usmeravanje imena domena na IP adresu korisnikove kućne mreže}

Ovo je poslednji korak u procesu konfigurisanja DDNS-a. Sada je zamenjena teško pamtljiva IP adresa sa lako pamtljivim imenom. Ova konfiguracija neće zameniti već postojeće postavke korisnikove kućne mreže, sve što je radilo pre postavljanja DDNS-a, nastaviće sa radom i sa novom adresom DDNS-a.

Ukoliko se korisnik ranije povezivao na kućni mužički server, dok je na poslu na primer, umesto što je posećivao XXX.XXX.XXX.XXX:5900 (kućna IP adresa, port 5900), sada može da se poveže na isti, unosom noveDDNSadrese.com:5900.

\subsection{Pristup testnom serveru preko DDNS-a}

Kreiran je primer test aplikacije za potrebe objašnjenja procesa deljenja pristupa korisnicima pomenutoj aplikaciji, upotrebom DDNS-a. Aplikacija je pokrenuta na lokalu, na portu 4000. Rezultat lokalnog pokretanja aplikacije je prikazan na Slika 2.

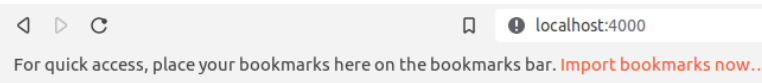

\section{Test server}

\section{Slika 2. Rezultat pokretanja aplikacije na lokalu}

Da bi korisnici bili u mogućnosti da pristupe aplikaciji, potrebno je da znaju IP adresu, a pošto je IP adresa $u$ ovom slučaju dinamička, prilikom promene te IP adrese, korisnici neće imati pristup aplikaciji. Da bi se zaobišao ovaj problem potrebno je da se konfiguriše DDNS, koji će dinamičku IP adresu pretvoriti u statičku. U ovom primeru su korišćene usluge No-IP provajdera, za registraciju domena i povezivanje sa ruterom. Na Slika 3. je prikazan primer kreiranog hostname-a (jeftic.ddns.net) na pomenutom provajderu.

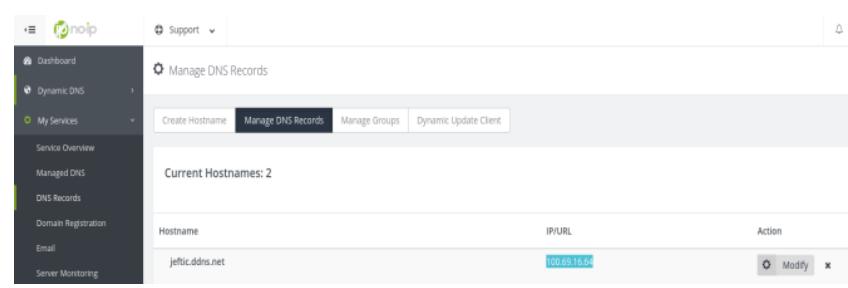

Slika 3. Kreiran hostname na No-IP provajderu

Sledeći korak jeste konfiguracija rutera. U odeljku za konfiguraciju DDNS-a, odabrati www.noip.com kao provajdera, uneti username, password i hostname. Prilikom klika na dugme „Save Settings“ dobiće se odgovor da li je hostname ažuriran. Na Slika 4. prikazan je izgled prethodno pomenutih konfiguracija.

DDNS

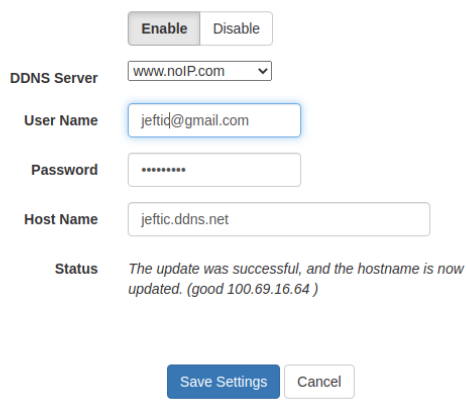

Slika 4. Konfiguracija DDNS-a na ruteru

Da bi se pristupilo test aplikaciji potrebno je mapirati spoljne portove na određeni računar i njegov interni port. U ovom slučaju spoljašnji port će biti 7777, koji će se mapirati na lokalni računar na kome je pokrenuta 
aplikacija, preko IP adrese tog računara (192.168.0.17) i porta na kome je pokrenuta aplikacija (4000). Mapiranje portova je prikazano na Slika 5.

Port Range Forwarding

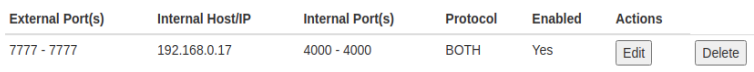

\section{Slika 5. Mapiranje portova}

Ovim je omogućeno korisnicima da pristupe test aplikaciji putem pretraživača, unošenjem adrese jeftic.ddns.net:7777. Na Slika 6. je prikazan krajnji rezultat.

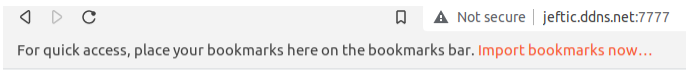

Test server

Slika 6. Krajnji rezultat konfiguracije DDNS-a

\section{ZAKLJUČAK}

Cilj obrađivanja ove teme je pojašnjenje načina na koji se može lako pristupiti kućnoj mreži sa bilo kog udaljenog mesta. Interpretirano rešenje nudi dinamički DNS. Kako bi bilo moguće implementirati ovu funkcionalnost, potrebno je da se korisnik opredeli za neki od provajdera koji nude DDNS.

Pored odabira provajdera, potrebno je još i odabrati ruter koji podržava DDNS, kako bi se na najlakši način omogućila ova funkcionalnost korisniku. Nakon implementacije svih potrebnih koraka, korisnik ima mogućnost da pristupi sadržaju na lokalnoj mreži, sa bilo kog mesta u svetu ukoliko ima pristup internetu i na taj način je $u$ mogućnosti da na primer, podeli svoj domen sa prijateljima ili da kreira lokalni server za neku igricu koji bi takođe podelio sa nekim korisnicima, ili jednostavno da omogući drugim korisnicima da pristupe njegovoj aplikaciji putem interneta, kao što je to objašnjeno u radu.

\section{LITERATURA}

[1] ,SAVREMENE IP MREŽE: ARHITEKTURE, TEHNOLOGIJE I PROTOKOLI“, Mirjana D. Stojanović, Vladanka S. Aćimović-Raspopović, 2012., Akademska Misao Beograd

[2] https://www.plus.rs/blog/osnove-funkcionisanja-dnsa-3/

[3] https://www.dynu.com/en-US/

\section{Kratka biografija:}

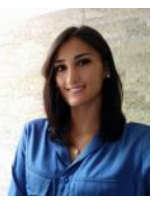

Vanja Jeftić rođena je u Novom Sadu 1997.

god. Master rad na Fakultetu tehničkih nauka iz oblasti Elektrotehnike i računarstva -

Primenjene računarske nauke odbranila je 2021.god.

kontakt: vanjajeftic97@gmail.com 